\title{
The association of manganese superoxide dismutase gene polymorphism (Rs4880) with diabetic macular edema in a cohort of type 2 diabetic Egyptian patients
}

Doaa M. Abdou ${ }^{1 *}$, Nesrine S. Mohammed ${ }^{2}$, Marwa El Fouli ${ }^{3}$, Hanan A. Medaney ${ }^{1}$, Sarah M. El Kateb ${ }^{1}$ and Safaa A. El-Gabrty ${ }^{1}$

\begin{abstract}
Background: Diabetic retinopathy (DR) and diabetic macular edema (DME) are the leading causes of blindness in patients with diabetes. Increasing numbers of people with diabetes worldwide suggest that DR and DME will continue to be major contributors to vision loss and associated functional impairment for years to come. Oxidative stress is a key participant in the development and progression of diabetes mellitus (DM) and its complications. Antioxidant status can affect vulnerability to oxidative damage, onset and progression of diabetes, and complications of diabetes. Manganese superoxide dismutase (Mn-SOD) is a key mitochondrial enzyme in cell defense against reactive oxygen species (ROS). DR and progression to DME have been associated with polymorphism in the second exon of the Mn-SOD gene at the 16th amino acid (Ala16Val) in the mitochondrial targeting sequence (MTS) of the protein. The study aimed to investigate the association between Ala16Val Mn-SOD gene polymorphism and the susceptibility to DR and DME in type 2 DM (T2DM).

Results: In this study, 150 patients with type 2 DM were enrolled: 100 patients with DR with and without diabetic macular edema (DME) and 50 patients with type 2 diabetes with a duration of 10 years without DR. Ala16Val SNP of the Mn-SOD gene (rs4880) was detected by TaqMan real-time PCR. The results showed that the homozygous polymorphic variant $W$ between the DME group is significantly higher than the non-DME group ( $P$ 0.018) among the DR group.
\end{abstract}

Conclusion: Mn SOD A16V polymorphism itself may not be associated with DR; meanwhile, it may be implicated in the pathogenesis of DME.

Keywords: Diabetic retinopathy, Mitochondrial targeting sequence, Diabetic macular edema, Mn-SOD gene, Ala16Val (rs 4880)

\footnotetext{
* Correspondence: doaa.mohamed@kasralainy.edu.eg

${ }^{1}$ Clinical and Chemical Pathology Department, Faculty of Medicine, Cairo

University, Giza 11562, Egypt

Full list of author information is available at the end of the article
}

\section{Springer Open}

(c) The Author(s). 2021 Open Access This article is licensed under a Creative Commons Attribution 4.0 International License, which permits use, sharing, adaptation, distribution and reproduction in any medium or format, as long as you give appropriate credit to the original author(s) and the source, provide a link to the Creative Commons licence, and indicate if changes were made. The images or other third party material in this article are included in the article's Creative Commons licence, unless indicated otherwise in a credit line to the material. If material is not included in the article's Creative Commons licence and your intended use is not permitted by statutory regulation or exceeds the permitted use, you will need to obtain permission directly from the copyright holder. To view a copy of this licence, visit http://creativecommons.org/licenses/by/4.0/. 


\section{Background}

Diabetic retinopathy (DR) is one of the most common microvascular complications of diabetes mellitus (DM). It is the main cause of blindness; it is subdivided into proliferative and non-proliferative subtypes. It may occur with or without diabetic macular edema (DME) [1]. DM results in the formation of advanced glycation end products and free oxygen radicals, leading to inflammation and the occurrence of DR and DME [2].

As the global prevalence of diabetes increases, the number of people with DR is growing, and it has been estimated to increase from 424.9 million in 2017 to 628 million, by 2045 [3]. DR may be classified as nonproliferative diabetic retinopathy (NPDR) and proliferative diabetic retinopathy (PDR) based on the presence of visible ophthalmological changes and the manifestation of retinal neovascularization [4].

$\mathrm{DR}$ is a multifactorial disease with an etiology that is complex. The exact mechanisms by which high blood glucose levels produce complications with diabetes is not entirely clear; however, it is known that hyperglycemia has metabolic effects that cause microvascular damage to the retina [5].

Different and heterogeneous factors such as hyperglycemia, growth factors, advanced glycation end products (AGEs), high levels of circulating or vitreous cytokines and chemokines, and reactive oxygen species (ROS) may trigger the inflammatory response of the retinal vasculature [6]. A large body of evidence, therefore, confirms that chronic inflammation is critical in the development of DR, particularly in the early stages [4].

Superoxide is a reactive oxygen species (ROS) molecule that should be maintained at nanomolar concentrations to prevent cell damage. Excessive quantities of ROS molecules cause damage to DNA and RNA proteins resulting in cell apoptosis, necrosis, and inflammation of endothelial vessels [7].

Manganese superoxide dismutase Mn-SOD is an antioxidant enzyme that causes mitochondrial superoxide radicals to be inactivated and dissipated into either ordinary molecular oxygen or hydrogen peroxide neutralized by catalase, resulting in protection against oxidative stress and cell damage [2].

Host genetic may contribute to the development of the diseases $[8,9]$. The encoding gene of the Mn-SOD enzyme is located on the long arm of chromosome 6q25.2. A single nucleotide polymorphism (SNP) 47C/T in the promoter region of the $M n-S O D$ gene $r s 4880$ at the 16th amino acid position in the second exon results in changes in the activity of this enzyme produced by the gene and accumulation of $\operatorname{ROS}[1,10,11]$.

Mn-SOD activity is affected by $47 C / T$ rs 4880 polymorphism due to structural changes in the mitochondrial targeting domain, resulting in a 30 to $40 \%$ decrease in Mn-SOD activity [12]. This polymorphism encodes for either (A) alanine or (V) valine. The presence of valine ( $\mathrm{V}$ allele) results in the production of unstable messenger RNA (mRNA) and a reduction in the transport of the enzyme to the mitochondrial matrix. This affects the severity of oxidative stress and reduces the efficacy of the enzyme, which means that the gene valley has a higher superoxide radical level than the A allele due to its lower ability to degrade $\mathrm{ROS}$ to $\mathrm{H}_{2} \mathrm{O}_{2}[10,13]$.

Accumulated ROS due to $M n-S O D$ gene polymorphism affects the progression of retinal disease in which retinal capillary cells undergo accelerated apoptosis in diabetics, causing diabetic retinopathy-characteristic histopathological changes [14].

The objective of this study is to demonstrate the association of Ala16 Val Mn-SOD gene variants with DR susceptibility and progression to DME in diabetes type 2 patients.

\section{Methods}

This is a case-control study from January 2018 to November 2019. The study included 150 patients with type 2 diabetes who were recruited from the Research Institute of Ophthalmology's outpatient clinic, Giza, Egypt. They were divided into two groups: group 1, 100 patients with DR with or without DME diagnosed based on the ophthalmology criteria [15]. Group 2 included 50 patients with type 2 diabetes without DR. The inclusion criteria for the patient group were type $2 \mathrm{DM}$ for more than 5 years, age $>25$ years, and the fundus examination showing typical DR blood vessel abnormalities, while the control group must be DR-free with a duration of more than 10 years. Patients with type 1 diabetes, diabetic patients with diabetic nephropathy or severe hypertension, and diabetes for less than 5 years were excluded from this study.

Both patients underwent a complete history of ophthalmological evaluation (visual acuity testing, Humphrey perimetry, optical coherence tomography, and fluorescein angiography), fundus examination, and laboratory investigations. Approval was obtained from the Ophthalmology department council of The Research Institute of Ophthalmology (reference no. I- 331016). All the procedures performed in the study were under the ethical standards of the Kasr Al-Ainy School of Medicine and with the 1964 Helsinki declaration and its later amendments or comparable ethical standards.

\section{Specimen collection}

Venous blood samples $(5 \mathrm{ml})$ were withdrawn from all subjects and evacuated to 2 sterile ethylenediaminetetraacetate EDTA vacutainer tubes. The first one $(3 \mathrm{ml})$ was used for DNA extraction while the second one $(2 \mathrm{ml})$ was used for HbA1c measurement. 


\section{HbA1c assay}

The HbA1c measurement was based on the turbidimetric inhibition immunoassay (TINIA) principle of the Dimension clinical chemistry auto analysis kits supplied by Siemens (Siemens Health Care Diagnostics Inc, 511 Benedict Ave/Tarrytown, NY10591) [16].

\section{Genotyping of $\mathrm{Mn}$-SOD (rs4880) variant}

Analysis of $M n-S O D$ polymorphism (rs 4880) using TaqMan pre-designed probes and primers was performed on Applied Biosystems Step One Real-time PCR. Genomic DNA was extracted from peripheral blood leukocytes using QIA amp DNA Mini kit-QIAGEN (Hoffmann-La Roche AG, Germany). Genotyping was performed using TaqMan fluorescently labeled with FAM or HEX and following the protocol recommended by the supplier (Applied Biosystems, USA). Negative controls were performed using the same DNA-free reaction mixtures. The amplification protocol for the PCR was as follows: initial activation of AmpliTaq Gold DNA Polymerase at $95{ }^{\circ} \mathrm{C}$ for $10 \mathrm{~min}$ followed by 50 denaturation cycles at $92{ }^{\circ} \mathrm{C}$ for $15 \mathrm{~s}$ and annealing and extension at $60{ }^{\circ} \mathrm{C}$ for $1 \mathrm{~min}[2,17]$.

After PCR amplification, an endpoint plate read was performed using Real-Time PCR System; the Sequence Detection System (SDS) software used the fluorescence measurements made during the plate read to plot fluorescence measurement values based on the signals from each well. Automatic allele calls have been made, and allele calls have been converted to genotypes [18].

\section{Statistical analysis}

Quantitative data were statistically described in terms of mean \pm standard deviation $( \pm \mathrm{SD})$ for parametric data, median for non-parametric data, and frequency and percentage for qualitative data. The odds ratio (OR) and the 95\% confidence interval $(\mathrm{CI})$ were calculated for the risk estimate. The comparison of numerical variables between study groups was performed using the Student $t$ test to compare 2 groups. To compare categorical data, the Chi-square $\left(\chi^{2}\right)$ test was performed. An exact test was used instead when the expected frequency is less than 5. $P$ values of less than 0.05 were considered statistically significant. All statistical calculations were made using SPSS (Statistics Package for Social Sciences; SPSS Inc., Chicago, IL, USA) version 15 for Microsoft Windows.

\section{Results}

One hundred and fifty patients have been enrolled in this case-control study divided into two groups: group I with DR which is further divided into two subgroups with DME and non-DME, and group II as a control group. The demographic and laboratory data for both groups are shown in Table 1.

The results showed that the age of onset of diabetes was statistically significantly lower in group I than in group II $(P<0.001)$. As far as a treatment modality is concerned, group II showed a statistically significant increase in the use of insulin injections compared to group $2(P<0.001)$.

The results also demonstrated that there was a statistically significant increase in the polymorphic VV genotype among patients with DME compared to those without DME (P 0.018). The frequency distribution of different genotypes in both DME and non-DME groups is shown in Table 2 and illustrated in Fig. 1.

Table 1 Comparison of demographic and laboratory data of diabetic with DR group and diabetic without DR group

\begin{tabular}{|c|c|c|c|}
\hline Index & Group 1 (diabetic with DR) $(n=100)$ & Group II (diabetic without DR) $(n=50)$ & $P$ value \\
\hline \multicolumn{4}{|l|}{ Sex } \\
\hline Male, $n(\%)$ & $6 / 100(46 \%)$ & 19/50 (38\%) & 0.351 \\
\hline Female, $n(\%)$ & $54 / 100(54 \%)$ & $31 / 50(62 \%)$ & \\
\hline DM duration (years)* & $18 \pm 6.8$ & $14 \pm 5.3$ & 0.000 \\
\hline Age of onset of diabetes (years)* & $40 \pm 10.5$ & $46.7 \pm 8$ & 0.000 \\
\hline \multicolumn{4}{|l|}{ Blood pressure state } \\
\hline Hypertensive & $55 / 100(55 \%)$ & $35 / 50(70 \%)$ & 0.077 \\
\hline Normotensive & $45 / 100(45 \%)$ & $15 / 50(30 \%)$ & \\
\hline \multicolumn{4}{|l|}{ Treatment modality } \\
\hline Insulin therapy & $77 / 100(77 \%)$ & $20 / 50(40 \%)$ & 0.000 \\
\hline Oral hypoglycemic therapy & 23/100 (23\%) & 20/50 (60\%) & \\
\hline HbA1c $(\%)^{*}$ & $8.7 \pm 1.6$ & $8.55 \pm 2$ & 0.561 \\
\hline FBS (mg/dl)* & $196 \pm 81$ & $184 \pm 87$ & 0.394 \\
\hline
\end{tabular}

Data are presented as number and percentage or * mean and SD, $P$ value $<0.05$ is significant FBS fasting blood sugar 
Table 2 Frequency distribution of different genotypes and alleles in DME and non-DME groups

\begin{tabular}{llll}
\hline Mn-SOD genotypes and alleles & Patients with DME, $\boldsymbol{N}$ 53 & Patients without DME, $\mathbf{N} \mathbf{4 7}$ & $\mathbf{P}$ value \\
\hline AA (wild) & $8(15.1)$ & $12(25.5 \%)$ \\
AV (heterozygous) & $22(41.5 \%)$ & $25(53.2 \%)$ \\
VV (homo-mutant) & $23(43.4 \%)$ & $10 .(21.3 \%)$ \\
Wild allele (A) & $50(51 \%)$ & $37(37.8 \%)$ \\
Mutant allele ( $V$ & $48(49 \%)$ & $61(62.2 \%)$ \\
\hline
\end{tabular}

Data are presented as number and percentage, $P$ value $<0.05$ is significant DME diabetic macular edema

The frequency distribution of different genotypes and alleles in both DR and non-DR patients had no significant difference between both groups concerning to the different distribution of genotypes $(P 0.3)$ or the distribution of alleles ( $P$ 0.120, OR 1.465, 95th CI 0.9-2.3) (Figs. 2 and 3).

The demographic, clinical, and laboratory data for the homozygous mutant, heterozygous, and wild genotype groups in the DR group are shown in Table 3 with no statistically significant differences in all groups for each variant.

\section{Discussion}

Diabetic retinopathy and diabetic macular edema are the results of chronic damage to retinal neurovascular structures affected by the duration of diabetes [19]. The pathophysiology of retinal damage remains uncertain but includes antioxidant imbalances and metabolic and neuroinflammatory insults [20]. Genetic variation in antioxidant genes such as $M n$-SOD leads to defect in the enzymatic activity and alteration of ROS detoxification, which may increase the risk of disease [1].

In the meantime, the results of this study showed a significant association between A16V polymorphism and the development of diabetic macular edema DME among diabetic patients with DR; the VV genotype was significantly higher in patients with DME than those without DME (P 0.018). This indicates that A16V polymorphism is a susceptible genetic factor for DME [21]. This finding is consistent with Zhang, J. et al. [22] who, meanwhile, revealed the association of A16V polymorphism with DME in diabetic patients; they found that the A-allele frequency among DME patients was significantly lower than that of non-DME patients $(P<0.05)$ [22].

One possible explanation was that $A 16 \mathrm{~V}$ polymorphism may be related to alteration of vascular permeability that causes DME rather than vascular occlusion related to DR, and A allele may protect against DME, and gene polymorphism was a susceptible genetic factor for DME [23]. The retina in particular is susceptible to oxidative stress due to its high proportion of polyunsaturated fatty acids, high consumption of oxygen, and exposure to visible light [1].

The results of the current study showed that there was no statistically significant difference between diabetic patients with retinopathy and diabetic without retinopathy for the different genotypes or allele distribution as regards $M n-S O D A 16 V$ polymorphism. (AA was 20\% versus $28 \%$, AV was $47 \%$ versus $50 \%$, and $\mathrm{VV}$ was $33 \%$ versus $22 \%)$ The results also showed no significant difference for the wild A allele (47.6\% versus $36.5 \%$ ) and mutant V allele (52.4\% versus 63.5\%) for peripheral DR and non-peripheral DR groups respectively $(P 0.125$, OR 0.5 , 95th CI 0.35-1.14). This finding was in agreement with another study, which previously revealed that $A 16 \mathrm{~V}$ polymorphism in $M n-S O D$ was not associated with DR

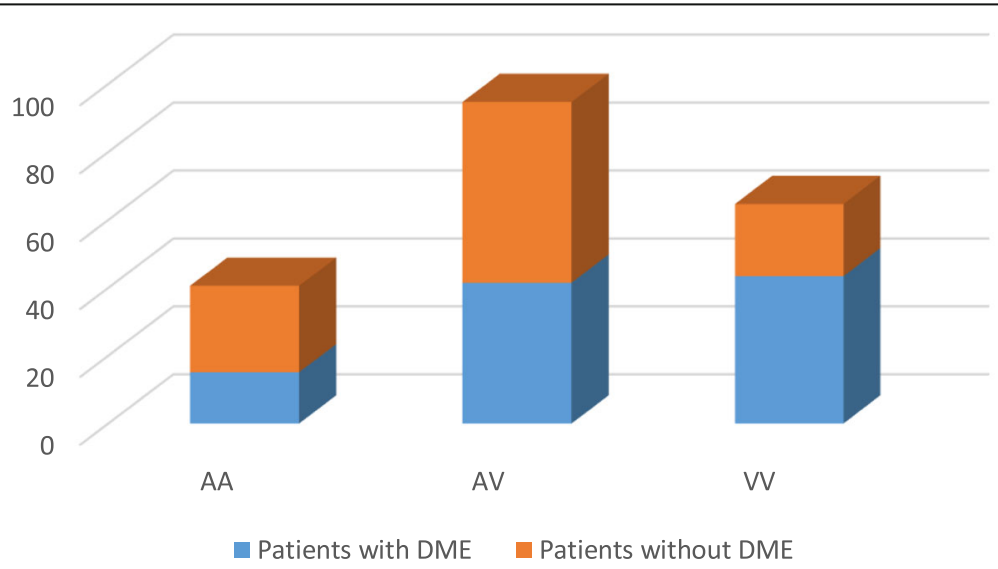

Fig. 1 Frequency distribution of different genotypes in DME and non-DME groups 


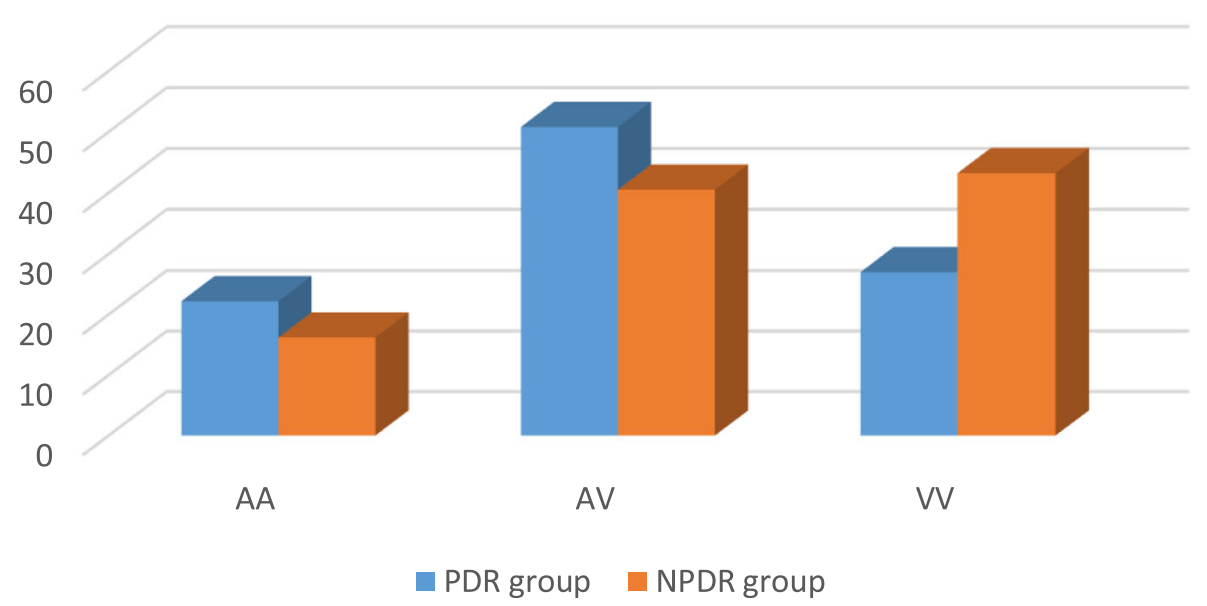

Fig. 2 Frequency distribution of different genotypes and alleles in peripheral DR and non-peripheral DR groups

but with a higher frequency of AA genotype in DR group (22.6\% in cases versus $19.3 \%$ in controls); also, the allele frequency was not statistically significantly different between the cases and control groups $(P$ 0.235) [24].

In contrast to the result of this study, Petrovic et al. revealed a significant association of $M n S O D$ polymorphism and DR as the VV polymorphic genotype was higher among the DR cases than in the control group 28.3\% versus $16.1 \%$ respectively $(P 0.006$, OR 2.1 , 95th CI1.23.4) [25]. Also Ye et al.'s study showed that the frequencies of VV genotype and V allele were significantly higher in the DR group than that in the diabetic without retinopathy group $(P$ 0.001). Their study showed that the $\mathrm{V}$ allele was associated with a 1.96-fold higher risk of development of DR (OR 1.96, 95th CI 1.29-2.97) [26].

In contrast to the hypothesis that the $\mathrm{V}$ allele could be a high-risk allele, Tian et al. in their study found a higher frequency of AA genotypes $(P$ 0.03) and A allele $(P$ 0.04) in the DR group (type 1 or type 2 ) compared to diabetics without retinopathy in the DR group [27].

The discrepancy between the results of this study and the previous results could be explained by the heterogeneity of the genetic background among populations, which supports the need for replication studies among all ethnic groups, particularly those with a high degree of heterogeneity. There was also a lack of standardization of the DR phenotype in different studies (i.e., studies did not show that the cases included were either peripheral DR-only or peripheral DR-type and non-peripheral DR-type; mild or severe form and, concerning for the control group, some studies enrolling diabetics without retinopathy, while others enrolling those with mild retinopathy background).

There is a possibility of interaction between $M n-S O D$ $A 16 \mathrm{~V}$ polymorphism, and other environmental factors not

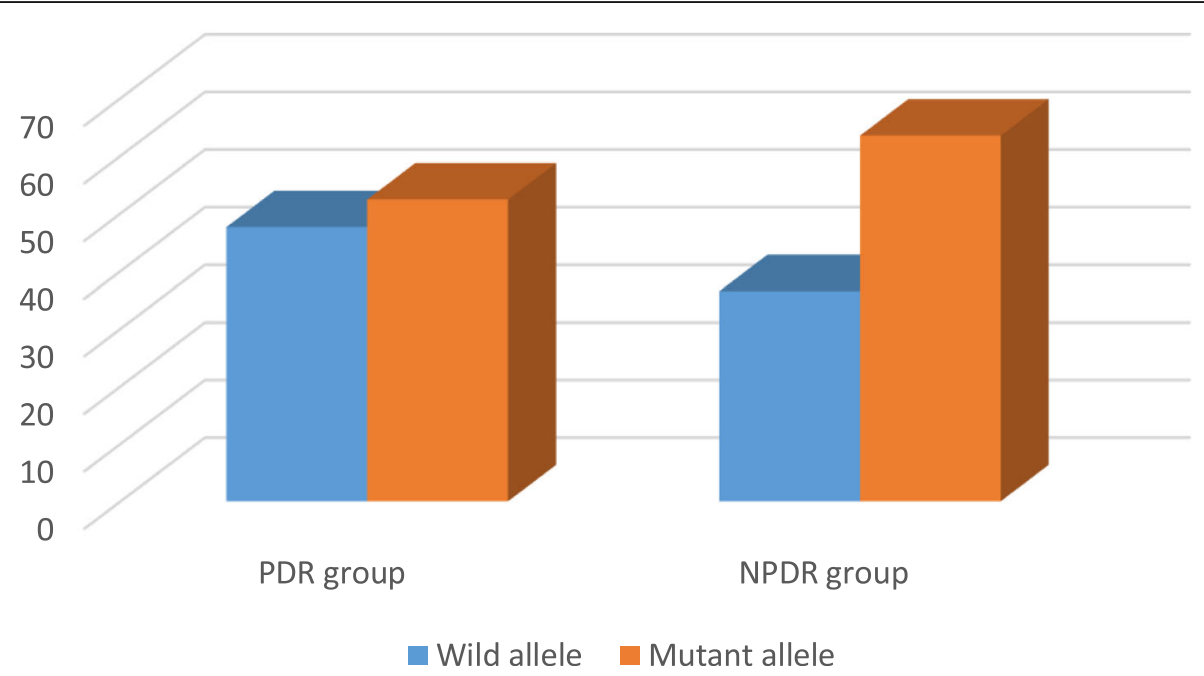

Fig. 3 Frequency distribution of different alleles in peripheral DR and non-peripheral DR groups 
Table 3 The demographic, clinical, and laboratory data of the homozygous mutant, heterozygous, and wild genotype groups among the DR group

\begin{tabular}{|c|c|c|c|c|}
\hline & $\begin{array}{l}\text { (Homozygous wild AA) } \\
N=20(\text { mean } \pm \text { SD) }\end{array}$ & $\begin{array}{l}\text { (Heterozygous AV) } \\
N=47(\text { mean } \pm \text { SD) }\end{array}$ & $\begin{array}{l}\text { (Homozygous mutant VV) } \\
N=33(\text { mean } \pm \text { SD })\end{array}$ & $P$ value \\
\hline Age $^{*}$ & $57.8 \pm 9.2$ & $56.8 \pm 9.2$ & $60.1 \pm 8.8$ & 0.278 \\
\hline \multicolumn{5}{|l|}{ Sex } \\
\hline Male $n(\%)$ & $8(40 \%)$ & $21(44.7 \%)$ & $17(51.5 \%)$ & \multirow[t]{2}{*}{0.695} \\
\hline Female $n(\%)$ & $12(60 \%)$ & $26(55.3 \%)$ & $16(48.5 \%)$ & \\
\hline DM duration* & $15.8 \pm 7.1$ & $18.4 \pm 6.4$ & $18.8 \pm 7.1$ & 0.254 \\
\hline Age of onset of diabetes* & $42 \pm 11.3$ & $38.43 \pm 10.2$ & $41.33 \pm 10.4$ & 0.320 \\
\hline \multicolumn{5}{|l|}{ Blood pressure state } \\
\hline Hypertensive & $13(65.0 \%)$ & $21(44.7 \%)$ & $21(63.6 \%)$ & \multirow[t]{2}{*}{0.148} \\
\hline Normotensive & $7(35.0 \%)$ & $26(55.3 \%)$ & $12(36.4 \%)$ & \\
\hline \multicolumn{5}{|l|}{ Treatment } \\
\hline Insulin $n(\%)$ oral & $16(80.0 \%)$ & $39(83.0 \%)$ & $22(66.7 \%)$ & \multirow[t]{2}{*}{0.219} \\
\hline Hypoglycemic $n$ (\%) & $4(20.0 \%)$ & $8(17.0 \%)$ & $11(33.3 \%)$ & \\
\hline $\operatorname{HbA1c}(\%)^{*}$ & $8.1 \pm 1$ & $8.8 \pm 1.7$ & $8.9 \pm 1.7$ & 0.199 \\
\hline + ve family history of DR & $4(14.8 \%)$ & $16(59.3 \%)$ & $7(25.9 \%)$ & 0.326 \\
\hline History of argon laser & $16(21.9 \%)$ & $37(50.7 \%)$ & $20(27.4 \%)$ & 0.146 \\
\hline History of vitrectomy & $6(18.8 \%)$ & $17(53.1 \%)$ & $9(28.1 \%)$ & 0.687 \\
\hline
\end{tabular}

Data are presented as number and percentage or * mean and SD, $P$ value $<0.05$ is significant

taken into account in this study, such as glucose level, smoking status, and dietary and plasma antioxidant capacity. Results of some studies have shown that this antioxidant status can have an oxidative stress effect in some patients, so the antioxidant status associated with diabetes and related diseases still needs to be clarified [28].

\section{Conclusion}

$M n-S O D A 16 V$ polymorphism itself may not be associated with DR; there may be mutations in other genes that may alter the formation of ROS as advanced glycation end products through their receptors and therefore influence the production of growth factors and cytokines that could be the cause of DR.

Further studies with a larger sample size from different populations are therefore needed to better understand the genes associated with diabetic retinopathy. In this way, biochemical mechanisms for the disease can be identified that help to develop new tools for the identification of patients at risk.

\footnotetext{
Abbreviations

DM: Diabetes mellitus; DME: Diabetic macular edema; DR: Diabetic retinopathy; EDTA: Ethylenediaminetetraacetate; Mn-SOD: Manganese superoxide dismutase; mRNA: Messenger RNA; MTS: Mitochondrial targeting sequence; NPDR: Non-proliferative diabetic retinopathy; PDR: Proliferative diabetic retinopathy; ROS: Reactive oxygen species; SDS: Sequence Detection System; SNP: Single nucleotide polymorphism; TINI: Turbidimetric inhibition immunoassay
}

\section{Acknowledgements}

Not applicable
Authors' contributions

DMA was responsible for manuscript writing. HAM was responsible for study design and protocol of practical work. NSM was responsible for patients' collection according to inclusion criteria. ME was responsible for samples' collection and preparation and follow-up of the practical work. SAE was responsible for doing the practical work. HAM and SME were responsible for revising the practical work, data analysis, and revising manuscript writing. All authors have read and approved the manuscript.

\section{Funding}

The study was funded by authors with no other funding agents or institutes.

Availability of data and materials

Available upon request

Ethics approval and consent to participate

All procedures performed in the study were under the ethical standards of Faculty of Medicine, Kasr Al-Ainy School of Medicine and with the 1964 Helsinki declaration and its later amendments or comparable ethical standards [E. C. N-18- 2018], and a written informed consent was obtained from each participant after a full explanation of the study protocol.

Consent for publication

Not applicable

Competing interests

The authors declare no competing interests.

\section{Author details}

${ }^{1}$ Clinical and Chemical Pathology Department, Faculty of Medicine, Cairo University, Giza 11562, Egypt. ${ }^{2}$ Clinical Pathology Department, Research Institute of Ophthalmology, Giza 12557, Egypt. ${ }^{3}$ Ophthalmology Department, Research Institute of Ophthalmology, Giza 12557, Egypt. 
Received: 18 November 2020 Accepted: 26 January 2021

Published online: 31 March 2021

\section{References}

1. Naser NM, Babeker SE, Abdo M, Ismail AM, Altoum S, Bakheet KH (2019) Association of MnSOD-47C/TGENE polymorphism (Rs 4880-47C/T) in Sudanese patient with diabetic retinopathy. Asian J Med Heal 15(1):1-9

2. Afonina I, Zivarts M, Kutyavin I, Lukhtanov E, Gamper H, Meyer RB (1997) Efficient priming of PCR with short oligonucleotides conjugated to a minor groove binder. Nucleic Acids Res 25(13):2657-2660

3. Thomas RL, Halim S, Gurudas S, Sivaprasad S, Owens DR (2019) IDF diabetes atlas: a review of studies utilising retinal photography on the global prevalence of diabetes related retinopathy between 2015 and 2018 Diabetes Res Clin Pract 157:107840. https://doi.org/10.1016/j.diabres.2019. 107840

4. Shafabakhsh R (2018) Association between microRNAs expression and signaling pathways of inflammatory markers in diabetic retinopathy, pp 7781-7787

5. Al-kharashi AS (2018) Role of oxidative stress, inflammation, hypoxia and angiogenesis in the development of diabetic retinopathy. Saudi Ophthalmol 32(4):318-323. https://doi.org/10.1016/j.sjopt.2018.05.002

6. Santiago AR et al (2018) Sweet Stress: Coping With Vascular Dysfunction in Diabetic Retinopathy 9:1-14. https://doi.org/10.3389/fphys.2018.00820

7. Bunn HF, Gabbay KH, Gallop PM (1978) The glycosylation of hemoglobin: relevance to diabetes mellitus. Science (80- ) 200(4337):21-27

8. Zhang J, Zhao T, Xu C, Huang J, Yu H (2017) Genetic susceptibility of lung cancer in Chinese population: an overview of systematic reviews and metaanalyses. J Evid Based Med 10(3):207-211

9. da Silva BR, Cirelli T, Nepomuceno R, Theodoro LH, Orrico SRP, Cirelli JA et al (2020) Functional haplotype in the interleukin8 (CXCL8) gene is associated with type 2 diabetes mellitus and periodontitis in Brazilian population. Diabetes Metab Syndr Clin Res Rev 14(6):1665-1672

10. Abbasi M, Daneshpour MS, Hedayati M, Mottaghi A, Pourvali K, Azizi F (2018) The relationship between MnSOD Val16Ala gene polymorphism and the level of serum total antioxidant capacity with the risk of chronic kidney disease in type 2 diabetic patients: a nested case-control study in the Tehran lipid glucose study. Nutr Metab 15(1):1-8

11. Chi CS (2015) Diagnostic approach in infants and children with mitochondrial diseases. Pediatr Neonatol 56(1):7-18. https://doi.org/10.1016/ j.pedneo.2014.03.009

12. Bresciani G, Cruz IBM, De Paz JA, Cuevas MJ, González-Gallego J (2013) The MnSOD Ala16Val SNP: relevance to human diseases and interaction with environmental factors. Free Radic Res 47(10):781-792

13. Colak E, Pap D, Nikolić L, Vicković S (2019) The impact of obesity to antioxidant defense parameters in adolescents with increased cardiovascular risk Uticaj gojaznosti na parametre antioksidantne zaštite kod adolescenata sa povećanim kardiovaskularnim rizikom. J Med Biochem 26: $1-9$

14. Masuda T, Shimazawa M, Hara H (2017) Retinal Diseases Associated with Oxidative Stress and the Effects of a Free Radical Scavenger (Edaravone), Oxidative Medicine and Cellular Longevity. Hindawi Publishing Corporation 2017. https://doi.org/10.1155/2017/9208489

15. Wong TY, Sun J, Kawasaki R, Ruamviboonsuk P, Gupta N, Lansingh VC et al (2018) Guidelines on diabetic eye care the International Council of Ophthalmology recommendations for screening, follow-up, referral, and treatment based on resource settings. Ophthalmology 125(10):1608-1622. https://doi.org/10.1016/j.ophtha.2018.04.007

16. Jeppsson JO, Kobold U, Barr J, Finke A, Hoelzel W, Hoshino T et al (2002) Approved IFCC reference method for the measurement of $\mathrm{HbA1C}$ in human blood. Clin Chem Lab Med 40(1):78-89

17. Kutyavin IV, Lukhtanov EA, Gamper HB, Meyer RB (1997) Oligonucleotides with conjugated dihydropyrroloindole tripeptides: base composition and backbone effects on hybridiration. Nucleic Acids Res 25(18):3718-3723

18. ThermoFisher Scientific. Real-time PCR Hand-Book. 2012:11(1):85-95.

19. Habbu K, Singh RP (2016) Anti-VEGF in diabetic retinopathy and diabetic macular edema. Expert Rev Ophthalmol 11(6):443-451

20. Roy MS, Klein R, O'Colmain BJ, Klein BEK, Moss SE, Kempen JH (2004) The prevalence of diabetic retinopathy among adult type 1 diabetic persons in the United States. Arch Ophthalmol 122(4):546-551
21. Souiden Y, Mallouli H, Meskhi S, Chaabouni Y, Rebai A, Chéour F et al (2016) MnSOD and GPx1 polymorphism relationship with coronary heart disease risk and severity. Biol Res 49(1):1-12

22. Zhang J, Ma J, Zhou N, Zhang B, An J (2015) Insulin use and risk of diabetic macular edema in diabetes mellitus: a systemic review and meta-analysis of observational studies. Med Sci Monit 21:929-936

23. Ciulla TA, Amador AG, Zinman B (2003) Diabetic retinopathy and diabetic macular edema: pathophysiology, screening, and novel therapies. Diabetes Care 26(9):2653-2664

24. Huang L, Lyu J, Liu QP, Chen C, Wang T (2017) MnSOD Val16Ala polymorphism associated with retinopathy risk in diabetes: a PRISMAcompliant meta-analysis of case-control studies. Int J Ophthalmol 10(4):639_ 645

25. Petrovič MG, Cilenšek I, Petrovič D (2008) Manganese superoxide dismutase gene polymorphism (V16A) is associated with diabetic retinopathy in Slovene (Caucasians) type 2 diabetes patients. Dis Markers 24(1):59-64

26. Ye LX, Yang MP, Qiu H, Guo KQYJ (2008) Association of the polymorphism in manganese superoxide dismutase gene with diabetic retinopathy in Chinese type2. Chinese Association (25):452-4

27. Tian C, Fang S, Du X, Jia C (2011) Association of the C47T polymorphism in SOD2 with diabetes mellitus and diabetic microvascular complications: a meta-analysis. Diabetologia. 54(4):803-811

28. Pourvali K, Abbasi M, Mottaghi A (2016) Role of superoxide dismutase 2 gene Ala16Val polymorphism and total antioxidant capacity in diabetes and its complications. Avicenna J Med Biotechnol 8(2):48-56

\section{Publisher's Note}

Springer Nature remains neutral with regard to jurisdictional claims in published maps and institutional affiliations.

\section{Submit your manuscript to a SpringerOpen ${ }^{\circ}$ journal and benefit from:}

- Convenient online submission

- Rigorous peer review

- Open access: articles freely available online

- High visibility within the field

- Retaining the copyright to your article

Submit your next manuscript at $>$ springeropen.com 